\title{
6 Panduan Dasar Manajer Manajemen SDM yang Tepat
}

\author{
Khurin Ainy \\ Universitas Nahdlatul Ulama Sidoarjo \\ khurinainy@protonmail.com
}

Suatu perusahaan bisa kehilangan arah, semangat dan tidak dapat tumbuh dengan baik tanpa sumber daya yang berkualitas. Untuk itu, dibutuhkan Manajemen sumber daya manusia (SDM) atau Human resource (HR). Semua perusahaan harus menyediakan ketersediaan sumber daya manusia yang profesional, representatif dan personal. Kebutuhan SDM ini tentu beragam dari suatu perusahaan ke perusahaan. Karena itu, diperlukan kepedulian untuk menemukan sumber daya manusia yang tepat.

Manajemen Sumber Daya Manusia adalah tanggung jawab untuk produktivitas dan hubungan konstruktif organisasi dengan karyawannya (Purnomo, Putri, \& Rosyidah, 2017). Hingga saat ini pun, perusahaan membutuhkan sumber daya manusia (SDM) yang tepat dan manajemen sumber daya manusia yang memadai. Berikut ini panduan sederhana untuk mengelola manajemen SDM. 


\section{Kebijaksanaan}

Manajer SDM tidak diharuskan oleh hukum untuk menjaga kerahasiaan informasi (walaupun banyak karyawan berpikir bahwa itu adalah rahasia). Anda bukan pengacara, dokter, atau pendeta, tetapi Anda akan berurusan dengan informasi rahasia sepanjang hari. Anda perlu tahu kapan harus membagikan dan kapan menyimpan informasi rahasia. Misalnya, jika seorang karyawan mendatangi Anda dengan masalah kesehatan yang memengaruhi pekerjaannya, apakah Anda memberi tahu manajernya? Jika Anda tahu bahwa seorang karyawan akan diberhentikan minggu depan, dan dia menyebutkan di barisan di kafetaria bahwa ia mengajukan penawaran ke rumah baru, apa yang harus Anda katakan? Ini adalah masalah yang sering muncul dalam HR. Anda perlu tahu cara menanganinya (Lucas, 2019). Mengelola organisasi membutuhkan manajemen SDM (Maula et al., 2017).

\section{Kenali Peran Anda}

Manajemen SDM sekarang diakui sebagai mitra strategis, fokusnya lebih pada keterlibatan karyawan, manajemen bakat, mendorong inovasi, memecahkan stereotip dan mengembangkan budaya kolaboratif. Memahami definisi strategis dari peran Anda dan kemudian menghubungkannya dengan 
rencana bisnis akan membantu Anda dalam merencanakan strategi yang sepenuhnya didorong oleh hasil (Sondhi, 2018). Manajemen Sumber Daya Manusia digunakan sebagai penunjang untuk meningkatkan perekonomian (Asitah et al., 2018).

\section{Berikan Perhatian Khusus pada Rekrutmen Staf}

Perekrutan staf SDM baru terbaik di dunia tidak akan membantu Anda jika onboarding Anda tidak lengkap, tetapi seringkali orang dapat melupakan dengan tepat apa dampaknya. Jika karyawan baru Anda tidak berhasil, itu tidak hanya membuang waktu dan sumber daya yang dihabiskan untuk melatih mereka. Ini secara aktif mengurangi kinerja seluruh tim Anda dan semua orang yang pekerjaannya dalam beberapa cara terkait dengan karyawan baru. Inilah sebabnya mengapa orientasi karyawan sangat penting, dan mengapa mengikutsertakan semua orang dalam budaya sentral sangat penting untuk kesuksesan bisnis yang berkelanjutan. Untuk dengan cepat menerobos elemen-elemen agar dapat secara efektif mengarahkan karyawan Anda: Siapkan peralatan mereka dan sumber daya apa pun yang diperlukan di muka, Tetapkan beberapa mentor untuk menjadikan pengalaman lebih baik dan lebih efektif untuk semua pihak, Gunakan proses yang terdokumentasi untuk 
dengan cepat mempercepat mereka, Sentuh dasar dengan mereka secara teratur untuk memastikan semuanya berjalan lancar, Perkenalkan mereka ke seluruh tim mereka lebih awal, Pastikan semua orang tahu siapa yang bertanggung jawab untuk apa, dan siapa yang dipekerjakan dapat meminta saran tentang topik tertentu, Tetapkan harapan (baik untuk perusahaan, dan apa yang dapat diharapkan karyawan) dengan jelas dan sejak dini, Tambahkan sentuhan pribadi dengan menanyakan karyawan apa permen favorit mereka dalam wawancara mereka, lalu minta sepotong yang duduk di meja mereka datang pada hari pertama mereka. Jika Anda ingin membawa hal-hal ke tingkat berikutnya (atau hanya menyelamatkan diri Anda dari upaya membangun proses orientasi dari awal), lihat proses awal orientasi karyawan baru kami. Mereka sepenuhnya gratis, dan Anda bisa menggunakannya atau mengeditnya untuk kebutuhan spesifik Anda (Mulholland, 2017). Manajemen SDM dibutuhkan oleh semua institusi (Sholichah et al., 2017).

\section{Jangan Menghambat Pertumbuhan}

Memimpin orang berarti memungkinkan pertumbuhan SDM. Pemimpin yang kuat tidak menghambat pertumbuhan anggota tim SDM mereka, mereka membimbing mereka dan mendorong mereka untuk menggunakan 
keterampilan dan pengetahuan tingkat tertinggi mereka. Sering ada banyak kredit dan penghargaan untuk dibagikan. Sudah menjadi sifat manusia untuk ingin menumbuhkan dan memperluas karier Anda; ini berlaku untuk semua anggota tim Anda. Dorong mereka untuk membagikan ide terbaik mereka dan ketika mereka melakukannya, beri mereka hadiah dengan memberi mereka penghargaan yang layak mereka terima. Jika Anda menghambat pertumbuhan mereka, itu adalah jaminan Anda akan menghambat kinerja dan produktivitas seluruh tim Anda, serta diri Anda sendiri. Pertumbuhan pribadi dan profesional adalah hal yang baik untuk semua pihak yang terlibat (Alexander, 2019). Pengalaman dan keberhasilan menunjukkan manajemen SDM berperan bagi organisasi (Nahdiyah et al., 2017).

\section{Cara Merekrut SDM}

Perekrutan dan perekrutan melibatkan lebih dari sekadar membuat orang masuk. Ini juga pekerjaan Public Relation. Mengapa? Karena setiap kandidat akan meninggalkan proses lamarannya dengan perasaan tentang perusahaan Anda. Jika perekrut tidak responsif, ia akan pergi dengan perasaan buruk, dan bahkan jika ia paling cocok untuk pekerjaan Anda, ia mungkin tidak akan mengambil pekerjaan itu karena perekrut tidak efektif. Memahami di mana menemukan kandidat 
yang hebat, dan bagaimana cara membawa mereka, adalah keterampilan SDM yang kritis (Lucas, 2019).

\section{Pelatihan Keterampilan yang Relevan}

Praktik terbaik SDM ini menyatakan bahwa perusahaan harus banyak berinvestasi dalam waktu dan anggaran pelatihan untuk karyawannya. Setelah merekrut orang-orang terbaik, Anda perlu memastikan bahwa mereka tetap menjadi yang terdepan di lapangan. Ini menjadi lebih relevan saat ini karena laju perkembangan teknologi tumbuh secara eksponensial. Di sinilah pembelajaran dan pengembangan masuk (Vulpen, 2018). Semua organisasi membutuhkan manajemen SDM yang mumpuni (Munjidah, et al., 2017).

\section{References}

Alexander, M. (2019). 5 HR Management Tips to Improve Team Performance. Retrieved June 4, 2019, from

https://www.techrepublic.com/article/5-hrmanagement-tips-to-improve-teamperformance/ 
Asitah, N., Maula, I., Munjidah, A., Nahdiyah, K., Yuniarti, D., Sholichah, S. A., Purnomo, A., Rosyidah, E., Anam, F., Achmadi, A.K., \& Fahmi, M. (2018, May 25). Urgensi Aktualisasi Manajemen Sumber Daya Manusia untuk Resurgensi Perekonomian di Sidoarjo.

http://doi.org/10.17605/OSF.IO/TG79P

Lucas, S. (2019). 10 Skills Every HR Manager Needs to Succeed. Retrieved May 28, 2019, from

https://www.thebalancecareers.com/skills-hrmanagers-need-to-succeed-4138124

Maula, I., Mufidah, F.I., Rosyidah, E., \& Purnomo, A. (2017). SD Antawirya Islamic Javanese School Mother is Culture. In Wirausaha Pendidikan Indonesia (Jilid 1). Sidoarjo: Unusida Press.

Mulholland, B. (2017). 12 HR Management Tips to Run an Effective Business (and Prevent Total Chaos). Retrieved June 3, 2019, from https://www.process.st/hr-management-tips/

Munjidah, A, Zannah, I.P.N., Purnomo, A., Rosyidah, E. (2017). MI Thoriqussalam Berpegang Kepada Rosul. In Wirausaha Pendidikan Indonesia (Jilid 4). Sidoarjo: Unusida Press. 
Nahdiyah, K., Amrina, S., Purnomo, A., \&

Rosyidah, E. (2017). SD Taman Pendidikan

Islam Porong Iman Kuat Bekal di Akhirat. In

Wirausaha Pendidikan Indonesia (Jilid 2).

Sidoarjo: Unusida Press.

Purnomo, A., Putri, R. A., \& Rosyidah, E. (2017).

Kamus Manajemen Sumber Daya Manusia.

Sidoarjo: UNUSIDA Press.

Sholichah, S.A., Istiqomah, A., Rosyidah, E., \&

Purnomo, A. (2017). MI Darun Najah Berfikir

Berkarya Berdzikir. In Wirausaha Pendidikan

Indonesia (Jilid 3). Sidoarjo: Unusida Press.

Sondhi, P. (2018). Be an Outstanding HR

Professional with these 7 Tips. Retrieved May 28, 2019, from

https://www.entrepreneur.com/article/312894

Vulpen, E. van. (2018). 7 Human Resource Best

Practices (A mini-guide to HRM). Retrieved

June 5, 2019, from

https://www.digitalhrtech.com/human-

resource-best-practices/ 